\title{
Effects of Redox Disturbances on Intestinal Contractile Reactivity in Rats Fed with a Hypercaloric Diet
}

\author{
Iara L. L. de Souza, ${ }^{1,2}$ Elba dos S. Ferreira, ${ }^{1}$ Anderson F. A. Diniz, ${ }^{1}$ \\ Maria Thaynan de L. Carvalho, ${ }^{3}$ Fernando R. Queiroga, ${ }^{1}$ Lydiane T. Toscano, ${ }^{4}$ \\ Alexandre S. Silva, ${ }^{4}$ Patrícia M. da Silva, ${ }^{5}$ Fabiana de A. Cavalcante ${ }^{(D)},{ }^{1,2}$ \\ and Bagnólia A. da Silva ${ }^{10}{ }^{1,6}$
}

\author{
${ }^{1}$ Programa de Pós-graduação em Produtos Naturais e Sintéticos Bioativos, Centro de Ciências da Saúde, Universidade Federal \\ da Paraíba, João Pessoa, PB, Brazil \\ ${ }^{2}$ Departamento de Fisiologia e Patologia, Centro de Ciências da Saúde, Universidade Federal da Paraíba, João Pessoa, PB, Brazil \\ ${ }^{3}$ Centro de Ciências da Saúde, Universidade Federal da Paraíba, João Pessoa, PB, Brazil \\ ${ }^{4}$ Departamento de Educação Física, Centro de Ciências da Saúde, Universidade Federal da Paraíba, João Pessoa, PB, Brazil \\ ${ }^{5}$ Programa de Pós-graduação em Biologia Celular e Molecular, Centro de Ciências Exatas e da Natureza, Universidade Federal \\ da Paraíba, João Pessoa, PB, Brazil \\ ${ }^{6}$ Departamento de Ciências Farmacêuticas, Centro de Ciências da Saúde, Universidade Federal da Paraíba, João Pessoa, PB, Brazil
}

Correspondence should be addressed to Bagnólia A. da Silva; bagnolia@ltf.ufpb.br

Received 23 June 2018; Accepted 27 September 2018; Published 25 October 2018

Academic Editor: Jeferson L. Franco

Copyright (C) 2018 Iara L. L. de Souza et al. This is an open access article distributed under the Creative Commons Attribution License, which permits unrestricted use, distribution, and reproduction in any medium, provided the original work is properly cited.

\begin{abstract}
Few studies have associated the effects of changes in caloric intake and redox disturbances in the gastrointestinal tract. Therefore, the present study aimed at evaluating the hypercaloric diet consumption influence on the contractile reactivity of intestinal smooth muscle, morphology, and oxidative stress of rat ileum. Wistar rats were randomly divided into groups that received a standard diet and fed with a hypercaloric diet for 8 weeks. Animals were euthanized, and the ileum was isolated to isotonic contraction monitoring. Morphology was evaluated by histological staining and oxidative stress by quantification of malondialdehyde levels and total antioxidant activity. Cumulative concentration-response curves to $\mathrm{KCl}$ and carbachol were attenuated in rats fed with a hypercaloric diet compared to those that received a standard diet. In addition, an increase in caloric intake promotes a rise in the thickness of the longitudinal smooth muscle layer of rat ileum and tissue malondialdehyde levels, characterizing lipid peroxidation, as well as a decrease in the antioxidant activity. Thus, it was concluded that the consumption of a hypercaloric diet impairs rat intestinal contractility due to mechanisms involving modifications in the intestinal smooth muscle architecture triggered by redox disturbances.
\end{abstract}

\section{Introduction}

World Health Organization (WHO) defines obesity as a chronic condition characterized by an excessive accumulation of adipose tissue that causes health risk [1]. Therefore, obesity is categorized in the 10th revision of the International
Classification of Diseases (ICD-10) at endocrine, nutritional, and metabolic diseases section [2].

Currently, several models develop obesity in animals through genetic mutations. However, most cases of human obesity are considered polygenic because of several gene integration. Thus, when analyzing the genesis of obesity in 
humans, the induction of this disease in animals through the consumption of highly palatable and hypercaloric diets is indicated as the most appropriate [3].

Recently, our research group established a model of erectile dysfunction in Wistar rat associated to a hypercaloric diet consumption and characterized by an increase in body adiposity, endothelial dysfunction, and systemic oxidative stress [4]. The integral role of oxidative stress in the genesis of diseases affecting smooth muscle cells has been highlighted, mainly due to evidence of free radicals influence on contractility and/or relaxation of smooth muscle cells $[5,6]$.

The reactive oxygen species (ROS) are signaling agents under physiological conditions and control healing processes, apoptosis, and maintenance of smooth muscle tone and proliferation of this tissue, among others [7, 8]. ROS include a variety of free radicals, such as superoxide anion $\left(\mathrm{O}^{2-}\right)$ and hydroxyl radicals $\left(\mathrm{OH}^{-}\right)$, as well as nonradical oxygen derivatives such as hydrogen peroxide $\left(\mathrm{H}_{2} \mathrm{O}_{2}\right)$, hypochlorous acid $(\mathrm{HClO})$, peroxynitrite $\left(\mathrm{ONOO}^{-}\right)$, and ozone $\left(\mathrm{O}_{3}\right)$ [9].

An imbalance resulting from overproduction of ROS can damage proteins, lipids, DNA, and other cellular components $[10,11]$. In order to contain the formation of these ROS, the organism presents enzymatic and nonenzymatic antioxidant systems, and both play a fundamental role in the prevention of oxidation resulting from ROS [12]. The enzymatic antioxidant system comprises superoxide dismutase (SOD), glutathione peroxidase (GSH-PX) and reductase (GSH-Rd), and catalase, which are the enzymes responsible for removing $\mathrm{O}^{2-}$, organic hydroperoxides, and $\mathrm{H}_{2} \mathrm{O}_{2}$, respectively $[13,14]$. The nonenzymatic system involves a group of antioxidants that can be complexed in compounds produced in vivo, such as glutathione, ubiquinone, and uric acid, and in compounds obtained directly from the diet such as a-tocopherol (vitamin E), $\beta$-carotene, ascorbic acid (vitamin $\mathrm{C}$ ), and phenolic compounds such as flavonoids $[11,15]$.

In view of this information, changes in the balance between oxidative stress and body antioxidant defenses, with a predominance of ROS, observed when there is an increase in caloric intake, raise the probability of the development of organic dysfunctions. However, few studies have reported the effect of a change in dietary pattern on intestinal disorders; despite the abnormalities on intestinal contraction are related to pathophysiological processes, such as constipation, diarrhea, and intestinal colic [16]. Therefore, the aim of this study was to investigate the influence of hypercaloric diet consumption on the contractile reactivity of intestinal smooth muscle, morphology, and oxidative stress on rat ileum.

\section{Materials and Methods}

2.1. Animals. Wistar rats (Rattus norvegicus), 2 months old (approximately $150 \mathrm{~g}$ ), were obtained from the Bioterium Professor Thomas George from Universidade Federal da Paraíba (UFPB). The animals were maintained under controlled ventilation and temperature $\left(21 \pm 1^{\circ} \mathrm{C}\right)$ with water ad libitum in a $12 \mathrm{~h}$ light-dark cycle (light on from 6 to $18 \mathrm{~h}$ ).
The experimental procedures were performed following the principles of guidelines for the ethical use of animals in applied etiology studies [17] and from the Conselho Nacional de Controle de Experimentação Animal of Brazil [18] and were previously approved by the Ethics Committee on Animal Use of UFPB (protocol no. 0201/14).

2.2. Groups and Diets. Animals were randomly divided into two groups (10 rats/group): rats that received a standard diet (Presence ${ }^{\circledR}$ ) containing by weight $23 \%$ protein, $63 \%$ carbohydrate, and $4 \%$ lipids with energy density $3.8 \mathrm{kcal} / \mathrm{g}$ (SD) and rats fed with a hypercaloric diet composed by a standard diet (Presence ${ }^{\circledR}$ ), milk chocolate, peanuts, and sweet biscuit in the proportion of $3: 2: 2: 1$ (HD) [19]. The hypercaloric diet containing by weight $23 \%$ protein, $45 \%$ carbohydrate, and $16 \%$ lipids with the energy density of $4.2 \mathrm{kcal} / \mathrm{g}$ was prepared weekly and supplied to animals as pellets [4]. The experimental groups were fed for 8 weeks.

2.3. Drugs. Potassium chloride $(\mathrm{KCl})$, calcium chloride $\left(\mathrm{CaCl}_{2}\right)$, magnesium chloride $\left(\mathrm{MgCl}_{2}\right)$, sodium chloride $(\mathrm{NaCl})$, and formaldehyde were purchased from Vetec Química Fina Ltda. (Brazil). Sodium bicarbonate $\left(\mathrm{NaHCO}_{3}\right)$ and glucose $\left(\mathrm{C}_{6} \mathrm{H}_{12} \mathrm{O}_{6}\right)$ were purchased from Dinâmica (Brazil). Sodium monobasic phosphate $\left(\mathrm{NaH}_{2} \mathrm{PO}_{4}\right)$, sodium hydroxide $(\mathrm{NaOH})$, and hydrochloric acid $(\mathrm{HCl})$ were purchased from Nuclear (Brazil). These substances, except glucose, $\mathrm{NaCl}$, and $\mathrm{NaHCO}_{3}$, were diluted in distilled water to obtain each solution, which was maintained under refrigeration.

Carbamylcholine hydrochloride (CCh) was purchased from Merck (USA). Cremophor ${ }^{\circledR}$, thiobarbituric acid, tetramethoxypropane, perchloric acid, Mayer's hematoxylin, and eosin were acquired from Sigma-Aldrich (Brazil). All substances were diluted in distilled water as needed for each experimental protocol. The carbogen mixture $\left(95 \% \mathrm{O}_{2}\right.$ and $5 \% \mathrm{CO}_{2}$ ) was obtained from White Martins (Brazil).

2.4. Ileum Isolation. Animals were euthanized by guillotine and the ileum was removed, cleaned of connective tissue and fat, immersed in physiological solution at room temperature, and bubbled with carbogen mixture $\left(95 \% \mathrm{O}_{2}\right.$ and $5 \%$ $\mathrm{CO}_{2}$ ). In order to record the isotonic contractions, ileum segments $(2-3 \mathrm{~cm})$ were individually suspended in organ baths $(5 \mathrm{~mL})$ by cotton yarn and registered on the smoked drum through levers coupled to kymographs (DTF) with a thermostatic pump model Polystat 12002 Cole-Parmer (Vernon Hills) that controlled the organ bath temperature.

The physiological solution of Tyrode was used and has the composition (in $\mathrm{mM}$ ) as follows: $\mathrm{NaCl}$ (150.0), $\mathrm{KCl}$ (2.7), $\mathrm{CaCl}_{2}$ (1.8), $\mathrm{MgCl}_{2}$ (2.0), $\mathrm{NaHCO}_{3}$ (12.0), $\mathrm{NaH}_{2} \mathrm{PO}_{4}$ (0.4), and D-glucose (5.5). The $\mathrm{pH}$ was adjusted to 7.4 , and the ileum was stabilized for $1 \mathrm{~h}$ under a resting tension of $1 \mathrm{~g}$ at $37^{\circ} \mathrm{C}$ and bubbled with a carbogen mixture [20].

2.5. Contractile Reactivity Measurement. The ileum was assembled as previously described. After a stabilization period of 30 min to verify the organ functionality, a contraction was induced with $30 \mathrm{mM} \mathrm{KCl}$. Subsequently, cumulative 
concentration-response curves were obtained to $\mathrm{KCl}$ $\left(10^{-3}-3 \times 10^{-1} \mathrm{M}\right)$ and CCh $\left(10^{-9}-3 \times 10^{-5} \mathrm{M}\right)$.

The contractile reactivity was evaluated based on the values of the maximum effect $\left(E_{\max }\right)$ and the negative logarithm of the molar concentration of a substance that produced $50 \%$ of its maximal effect $\left(\mathrm{pCE}_{50}\right)$ of both contractile agents, calculated from the concentration-response curves obtained. The maximum amplitude obtained from the SD group concentration-response curve was elected as $100 \%$, and the HD was assessed referring to it.

2.6. Histological Analysis. Ileum segments were assembled as previously described fixed in $10 \%$ formaldehyde solution and subjected to a standard histological procedure. This process was composed of the following steps: (1) tissue dehydration at increasing alcohol series of $70 \%$ for $24 \mathrm{~h}$ and 80,96 , and $100 \%$ (third bath) during $1 \mathrm{~h}$ each; (2) tissue diaphanization/bleaching with immersion in $100 \%$ xylene alcohol ( $1: 1)$ during $1 \mathrm{~h}$, followed by two baths in pure xylene during $1 \mathrm{~h}$ each; (3) tissue embedding in paraffin, wherein the sample was immersed in two baths of liquid paraffin (heated to $50^{\circ} \mathrm{C}$ ) during $1 \mathrm{~h}$ each. Then, samples were embedded in new paraffin.

The blocks obtained were cut to $5 \mu \mathrm{m}$ thick in crosssection of the ileum and stained with Mayer's hematoxylin/eosin [21]. Digital images of histological sections were obtained and analyzed with an optical microscope with an attached camera. In this analysis, two cross-sections per animal were photographed, and the second quadrant of the ileum circumference was used to measure both circular and longitudinal muscle layers using the Leica Qwin 3.1 software [22].

2.7. Assessment of Lipidic Peroxidation Levels. Lipid peroxidation was measured by the chromogenic product of 2thiobarbituric acid (TBA) reaction with malondialdehyde (MDA) that is a product formed as a result of membrane lipid peroxidation [23]. Therefore, ileum segments were homogenized with $\mathrm{KCl}(1: 1)$, and samples of tissue homogenate $(250 \mu \mathrm{L})$ were incubated at $37^{\circ} \mathrm{C}$ for $60 \mathrm{~min}$. After that, the mixture was precipitated with $35 \%$ perchloric acid and centrifuged at $1207 \mathrm{~g}$ for $20 \mathrm{~min}$ at $4^{\circ} \mathrm{C}$. Then, the supernatant was collected and $400 \mu \mathrm{L}$ of $0.6 \%$ TBA was added and incubated at $95-100^{\circ} \mathrm{C}$ for $1 \mathrm{~h}$. After cooling, the samples were read in a spectrophotometer at a wavelength of $532 \mathrm{~nm}$ (Biospectro, SP-220 model-Brazil). The determination of the MDA concentration was made by substituting the absorbance values in the MDA standard curve obtained on the basis of a standard solution $(1 \mu \mathrm{L}$ of $1,1,3,3$ - tetramethoxypropane in $70 \mathrm{~mL}$ distilled water) diluted in series of $250,500,750,1000,1250,1500,1750,2000,2250,2500$, 2750 , and $3000 \mu \mathrm{L}$ of distilled water.

2.8. Antioxidant Activity Assay. The ileum homogenate was assembled as previously described. In addition, an aliquot of $1.25 \mathrm{mg}$ of DPPH was diluted in ethanol $(100 \mathrm{~mL})$, kept under refrigeration, and protected from light. Then, $3.9 \mathrm{~mL}$ of DPPH solution was added with $100 \mu \mathrm{L}$ of the supernatant ileum homogenate on appropriate centrifuge tubes. These tubes were vortexed and left to stand for $30 \mathrm{~min}$, centrifuged at $1207 \mathrm{~g}$ for $15 \mathrm{~min}$ at $20^{\circ} \mathrm{C}$. Then, the samples were read in a spectrophotometer at a wavelength of $515 \mathrm{~nm}$ (Biospectro, SP-220 model-Brazil) [24].

Results were expressed as the percentage of the oxidation inhibition: $\mathrm{AOA}=100-\left(\left(\left(\mathrm{DPPH}^{\cdot} \mathrm{R}\right) \mathrm{S} /\left(\begin{array}{l}\mathrm{DPPH} \\ \mathrm{R}\end{array}\right)\right.\right.$ $\mathrm{W}) \times 100)$, where $\left(\mathrm{DPPH}^{\circ} \mathrm{R}\right) \mathrm{S}$ and $\left(\mathrm{DPPH}^{-} \mathrm{R}\right) \mathrm{W}$ correspond to the concentration of $\mathrm{DPPH}$ remaining after $30 \mathrm{~min}$, measured in the sample (S) and white (W) prepared with distilled water.

2.9. Statistical Analysis. Results were expressed as the mean and standard error of the mean (S.E.M.) and statistically analyzed using Student's $t$-test to the intergroup comparison. Cumulative concentration-response curves were fitted, and $\mathrm{pCE}_{50}$ values were obtained by nonlinear regression [25]. Values were significantly different when $p<0.05$. All data were analyzed by GraphPad Prism ${ }^{\circledR}$ version 5.01 (GraphPad Software Inc., USA), and the visualization of histological sections was performed on Q-Capture ${ }^{\circledR}$ Pro version 7.0 software.

\section{Results}

3.1. Contractile Reactivity Measurement. In the HD group, cumulative concentration-response curves to $\mathrm{KCl}$ $\left(10^{-3}-3 \times 10^{-1} \mathrm{M}\right)$ were attenuated with the reduction on $E_{\max }$ from $100 \%(\mathrm{SD})$ to $42.7 \pm 3.1 \%$. However, the $\mathrm{pCE}_{50}$ value of the $\mathrm{HD}$ group $\left(\mathrm{pCE}_{50}=1.8 \pm 0.8\right)$ showed no statistical difference compared to the SD group $\left(\mathrm{pCE}_{50}=1.8 \pm 0.2\right)$ (Figure 1(a), Table 1, $n=5$ ).

Meanwhile, cumulative concentration-response curves to CCh $\left(10^{-9}-3 \times 10^{-5} \mathrm{M}\right)$ were shifted to the right in rats fed with a hypercaloric diet $\left(\mathrm{pCE}_{50}=6.6 \pm 0.1\right)$ compared to the $\mathrm{SD}$ group $\left(\mathrm{pCE}_{50}=6.3 \pm 0.05\right)$. In addition, $E_{\max }$ value was decreased on HD related to SD $\left(E_{\max }=32.7 \pm 7.5\right.$ and $100 \%$, respectively), changing both potency and efficacy of $\mathrm{CCh}$ (Figure 1(b), Table 1, $n=5$ ).

3.2. Histological Analysis. The circular smooth muscle layer thickness of rat ileum has no significant difference between HD $(48.3 \pm 4.0 \mu \mathrm{m})$ and SD groups $(47.0 \pm 1.8 \mu \mathrm{m})$. However, the longitudinal smooth muscle layer of rat ileum presented an increased thickness on rats fed with a hypercaloric diet compared to that in the SD group (36.53 \pm 4.6 and $29.0 \pm 1.9 \mu \mathrm{m}$, respectively) (Figure 2, $n=5$ ).

3.3. Assessment of Lipidic Peroxidation Levels. The MDA levels in rat ileum were increased from $5.4 \pm 0.2 \mu \mathrm{M} / \mathrm{L}$ (SD) to $7.0 \pm 0.3 \mu \mathrm{M} / \mathrm{L}$ in rats fed with a hypercaloric diet (Figure 3(a), $n=5$ ).

3.4. Antioxidant Activity Assay. The antioxidant activity in rat ileum was decreased from $93.0 \pm 1.4 \%$ (SD) to 77.5 $\pm 1.5 \%$ in rats fed with a hypercaloric diet (Figure $3(\mathrm{~b})$, $n=5)$.

\section{Discussion}

In this work, the influence of hypercaloric diet consumption on the contractile reactivity, morphology, and oxidative 


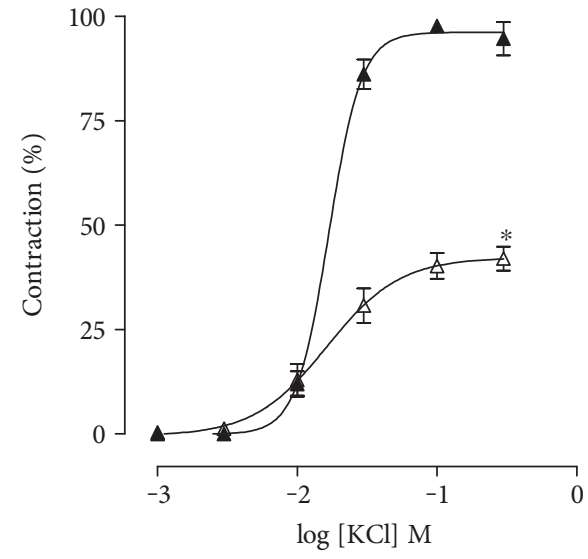

(a)

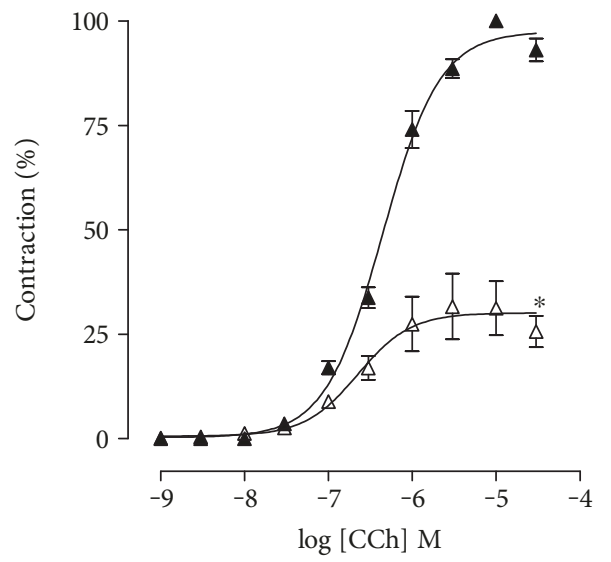

(b)

Figure 1: Cumulative concentration-response curves to $\mathrm{KCl}(\mathrm{a})$ and $\mathrm{CCh}(\mathrm{b})$ in rat ileum from both $\mathrm{SD}(\mathbf{\Delta})$ and $\mathrm{HD}$ groups $(\Delta)$. The symbols and vertical bars represent the mean and S.E.M., respectively $(n=5)$. Student's $t$-test, ${ }^{*} p<0.05$ (SD vs. HD).

TABLE 1: Values of $E_{\max }(\%)$ and $\mathrm{pCE}_{50}$ of $\mathrm{KCl}$ and $\mathrm{CCh}$ in rat ileum from both SD and HD groups. Student's $t$-test, ${ }^{*} p<0.05$ (SD $v$. $\mathrm{HD})(n=5)$.

\begin{tabular}{lcccc}
\hline \multirow{2}{*}{ Groups } & \multicolumn{2}{c}{$\mathrm{KCl}$} & \multicolumn{2}{c}{$\mathrm{CCh}$} \\
& $E_{\max }(\%)$ & $\mathrm{pCE}_{50}$ & $E_{\max }(\%)$ & $\mathrm{pCE}_{50}$ \\
\hline SD & 100 & $1.8 \pm 0.2$ & 100 & $6.3 \pm 0.05$ \\
$\mathrm{HD}$ & $42.7 \pm 3.1^{*}$ & $1.8 \pm 0.8$ & $32.7 \pm 7.5^{*}$ & $6.6 \pm 0.1^{*}$ \\
\hline
\end{tabular}

stress in rat ileum was investigated, demonstrating that an increase in caloric intake is associated with a decrease in contractile reactivity, an increase in the longitudinal smooth muscle layer thickness, lipid peroxidation, and a decrease in the antioxidant activity of this organ.

Chronic noncommunicable diseases (NCDs), such as type 2 diabetes mellitus, dyslipidemias, hypertension, and obesity, play an important and growing role in global public health due to their disabilities and early mortality. In this view, a central part of the genesis of these diseases is the excessive increase in body adiposity [26].

There are many determinants of obesity, being, therefore, a multifactorial disease characterized by the abnormal or excessive accumulation of adipose tissue [1]. Basically, obesity is caused by genetic and environmental factors, which are associated to an imbalance between energy expenditure and caloric consumption that are often determined by the consumption of diets with high energy density and high levels of fat and sugar [27, 28].

The ethical limitation in studying the mechanisms by which obesity induces physiological disorders in humans has resulted in the creation of experimental models using animals that are induced mainly by dietary and/or endocrine manipulation [29]. In these models, it is known that the consumption of hypercaloric/hyperlipidic diets is directly related to the development of various metabolic and hemodynamic disorders that result in adipose tissue hypertrophy/hyperplasia $[30,31]$.
Nevertheless, few studies have investigated the association of metabolic dysfunctions arising from the consumption of hypercaloric diets with possible alteration of cavernous smooth muscle reactivity on rats. Newly, Wistar rats fed with a hypercaloric diet, during eight weeks, showed increased systemic oxidative stress as well as impairment of contractile and relaxing reactivity of the corpus cavernosum in both pharmaco- and electromechanical couplings [4]. However, there is a lack of information about possible changes in intestinal contractile reactivity due to hypercaloric diet consumption, regarding the caloric content as well as the diet composition.

In view of these premises, it was decided to investigate whether the consumption of this diet, for eight weeks, would also alter the Wistar rats' intestinal contractile reactivity. Thus, the effect of the consumption of hypercaloric diet on both electro- and pharmacomechanical couplings was tested using $\mathrm{KCl}$ and $\mathrm{CCh}$, respectively. The $\mathrm{KCl}$ was employed to simulate alterations on the membrane potential, which are physiologically controlled by the pacemaker of interstitial cells of Cajal located at the boundaries and in the substance of the inner circular muscle layer from which they spread to the outer longitudinal muscle layer. The CCh was used to mimic the cholinergic stimulation that happens in the intestinal smooth muscle $[32,33]$.

In this study, the $\mathrm{KCl}$ contractile efficacy was reduced in rats fed with hypercaloric diet in relation to those that received standard diet, with no change in potency (Figure 1(a), Table 1). Rembold [34] that verified an attenuation in cumulative concentration-response curves to $\mathrm{KCl}$ in rat ileum, decreasing its efficacy without changing the contractile potency, obtained similar results due to exercise. Thus, it is shown that an increase in caloric intake reduces the contraction elicited by the electromechanical coupling of rat ileum.

In addition, when rats consumed hypercaloric diet, a reduction was observed in both contractile efficacy and potency of CCh (Figure 1(b), Table 1). Data obtained by Araujo et al. [35] have demonstrated a similar decrease in 


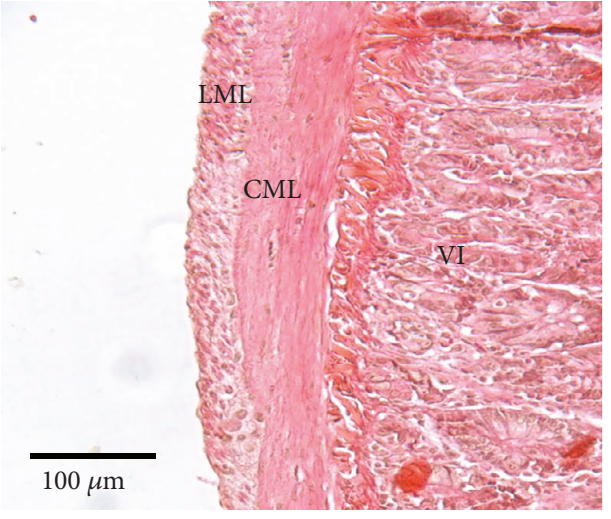

(a)

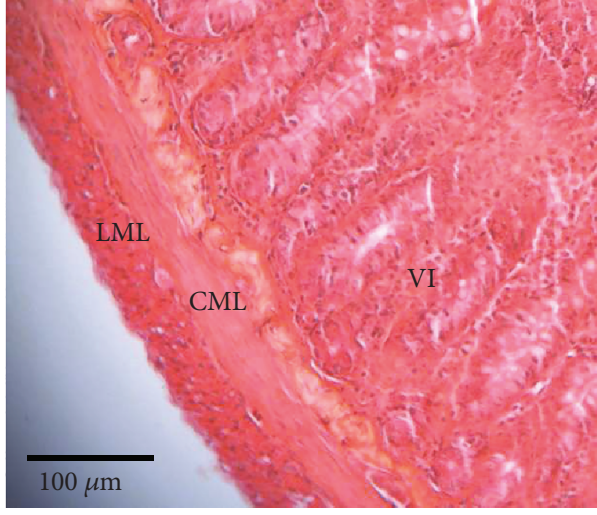

(b)

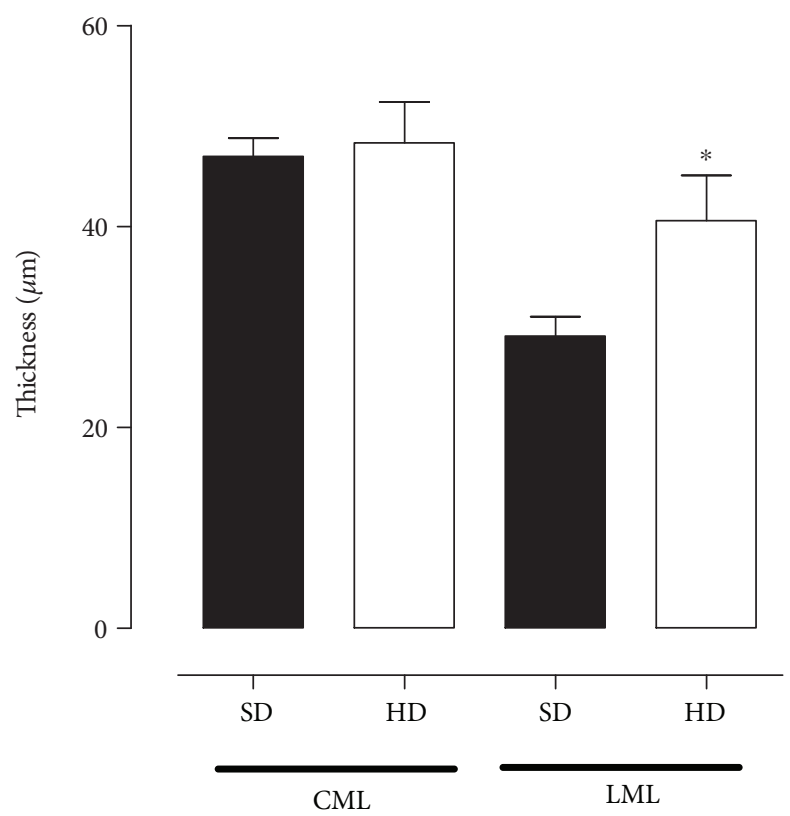

(c)

Figure 2: Microphotography of rat ileum from both SD (a) and HD groups (b) and thickness of CML and LML (c). Increased lens 20x. The symbols and vertical bars represent the mean and S.E.M., respectively $(n=5)$. Student's $t$-test, ${ }^{*} p<0.05(\mathrm{SD} v s . \mathrm{HD})$. CML $=$ circular muscle layer; $\mathrm{LML}=$ longitudinal muscle layer; $\mathrm{VI}=$ villus.

both efficacy and potency of CCh in the ileum of rats submitted to acute aerobic swimming exercise that were associated to a possible desensitization of intestinal muscarinic receptors. Moreover, the reperfusion process was also correlated to a reduction of $\mathrm{ACh}$-induced contractile response in the ileum of rats submitted to occlusion of superior mesenteric artery plus interruption of collateral blood flow, leading to reperfusion [36]. Therefore, we demonstrate that an increase in caloric intake reduces the contraction elicited by the pharmacomechanical coupling of rat ileum, due to a less response of smooth muscle cell to cholinergic stimulation.

The synchrony between the smooth muscle layers, a circular and a longitudinal layer, modulates the intestinal contractility. In this view, Bertoni et al. [37] showed that hypertrophy of the circular smooth muscle layer is associated to an increase in contractile efficacy, whereas hypertrophy of the longitudinal smooth muscle layer exhibits a greater sensitivity to the relaxing factors, leading to a decrease in contractile efficacy. Thus, as the present study demonstrated a reduced contractility of rat ileum (Figure 1) due to hypercaloric diet consumption, it was hypothesized that changes in the architecture of the intestinal smooth muscle could be responsible for these results.

Therefore, to verify this hypothesis, histological analyses were performed on rat ileum from both experimental groups. The circular smooth muscle layer thickness was not altered by the consumption of a hypercaloric diet (Figure 2). Interestingly, an increase in the longitudinal smooth muscle layer thickness was observed (Figure 2), characterizing a hypertrophy process. Based on these results, it can be proposed that an increase in caloric intake leads to longitudinal smooth muscle layer hypertrophy and, consequently, reduced the ileum contractility (Figures 1 and 2).

A common problem related to the pathogenesis of intestinal reactivity disorders is the presence of a chronic low-grade inflammation that results in adipose tissue 


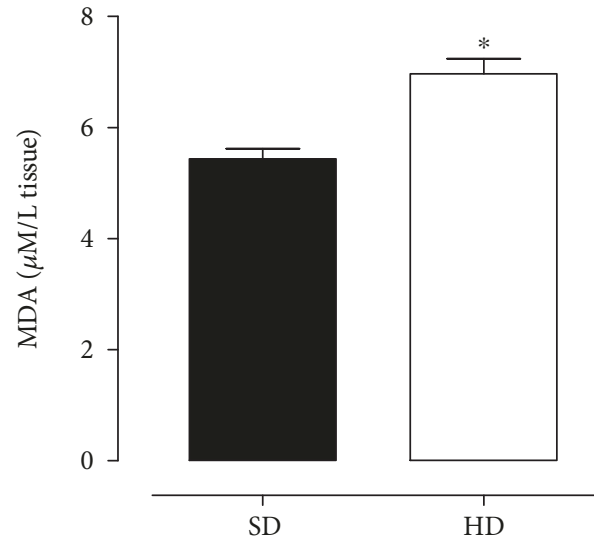

(a)

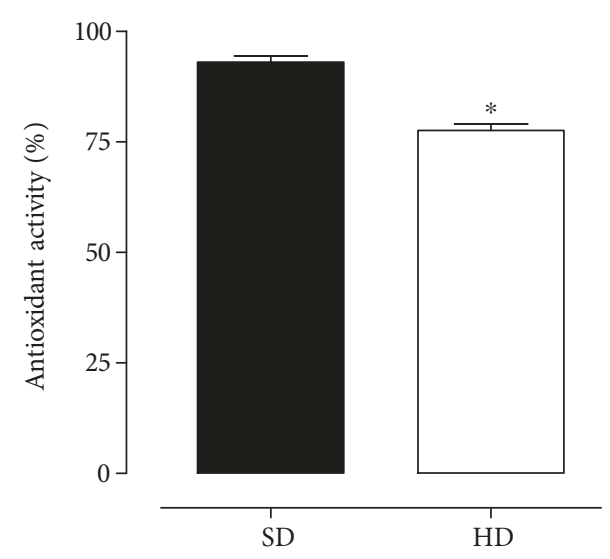

(b)

FIGURE 3: Concentration of MDA (a) and antioxidant activity (b) of rat ileum from both SD and HD groups. The symbols and vertical bars represent the mean and S.E.M., respectively $(n=5)$. Student's $t$-test, ${ }^{*} p<0.05$ (SD vs. HD). MDA = malondialdehyde.

hypertrophy [38]. Similar to other inflammatory processes, adipose tissue inflammation is a trigger for the oxidative stress and can be started by an increase in caloric intake. Briefly, due to the consumption of hypercaloric/hyperlipidic diets, there is an increase in glucose and circulating lipid levels resulting in the excessive supply of energetic substrates to metabolic routes. In turn, ROS production is raised, especially $\mathrm{O}^{2-}, \mathrm{H}_{2} \mathrm{O}_{2}$, and $\mathrm{OH}^{-}$, among others $[8,9]$.

It is consolidated in the literature that an imbalance in tissue peroxidation and antioxidant activity leads to oxidative damage, consequently, modulating both structure and/or function of the tissue [39-41]. Ischemia-reperfusion events in the intestinal musculature are closely related to oxidative stress [42], promoting motor and intestinal mucosa alteration, decrease in nutrient absorption, and gastrointestinal permeability $[43,44]$. Other processes that also alter redox homeostasis, such as physical exercise, have already been correlated to increased lipid peroxidation. Specifically, Araujo et al. [45] showed that chronic aerobic swimming exercise increases lipid peroxidation after four weeks of exercise. Based on this information, it was decided to investigate whether the consumption of a hypercaloric diet would also alter lipid peroxidation of rat ileum. For this, the levels of MDA, a lipid peroxidation marker, were evaluated.

In studies involving oxidative stress, MDA represents a compound formed through the oxidative decomposition of polyunsaturated fatty acids from the membrane and is the most frequently quantified systemic and tissue marker [46]. MDA levels are therefore quantified through a calorimetric reaction in which two molecules of thiobarbituric acid are condensed with a molecule of MDA, and the end product is detected by spectrophotometry technique [47].

According to this methodology, it was observed that MDA concentration was increased in rat ileum from the HD group in relation to the SD group (Figure 3(a)). Souza et al. [4], using the same hypercaloric diet, showed that rats had an increase in MDA levels in plasma, characterizing a systemic oxidative stress. The remarkable increase in the level of ileum peroxidation in the HD group (Figure 3(a)) is quite suggestive that hypercaloric diet consumption also promotes tissue peroxidation. Additionally, it is an important challenge for intestinal redox homeostasis and indicates a possible compromise of the antioxidant defense system of these animals. The peroxidation increase may be a consequence of proinflammatory cytokine production (TNF- $\alpha$, IL- 1 , and IL-6), due to excess body adiposity, since these cytokines stimulate ROS production by macrophages [48].

In biological systems, this imbalance in ROS production is counterbalanced by the body's antioxidant capacity, representing the body's ability to sequester free radicals through redox systems [49]. Knowing this, it was investigated whether the consumption of a hypercaloric diet would alter the antioxidant activity of these rats. For this, the DPPH reduction colorimetric method was used, which is based on the sample's ability to reduce the DPPH radical (purple) to 1,1-diphenyl 2-picryl hydrazine (translucent), detected by spectrophotometry technique [50].

In this study, the HD group presented a reduction in tissue antioxidant activity in relation to the SD group (Figure 3(b)). The decrease of systemic antioxidant activity was demonstrated by Souza et al. [4] using the same hypercaloric diet. Therefore, the reduction of the ileum antioxidant capacity observed in the HD group (Figure 3(b)) reinforces the idea of an imbalance between ROS production and antioxidant defense systems, correlated with an increase in MDA levels in these rats (Figure 3(a)). Since free radicals are regulators in several cellular processes, such as transcriptional factor activation, gene expression, and cell proliferation [7], it was proposed that an oxidative stress caused by the consumption of a hypercaloric diet may underlie the hypertrophy process of intestinal smooth muscle cells in rats (Figures 2 and 3 ).

In conclusion, the current study showed initial evidence that the consumption of a hypercaloric diet impairs rat intestinal contractility due to mechanisms involving modifications in the intestinal smooth muscle architecture triggered by redox disturbances. Thus, we provide a model to understand biochemical and metabolic processes involved in the pathophysiological changes caused by the increase in caloric intake, as well as to help to reduce the impact of the various diseases related to it. 


\section{Data Availability}

The data used to support the findings of this study are available from the corresponding author upon request.

\section{Conflicts of Interest}

The authors declare that there is no conflict of interest regarding the publication of this paper.

\section{Acknowledgments}

The authors thank Coordenação de Aperfeiçoamento de Pessoal de Nível Superior (CAPES) and Conselho Nacional de Desenvolvimento Científico e Tecnológico ( $\mathrm{CNPq}$ ) for financial support. The authors thank José Crispim Duarte and Luís C. Silva for providing technical assistance and Camila Leão Luna de Souza for English review.

\section{References}

[1] WHO, Health Topics - Obesity, WHO, 2018.

[2] WHO, Obesity: Preventing and Managing the Global Epidemic, WHO, 2000.

[3] T. A. LUTZ and S. C. WOODS, "Overview of animal models of obesity," Current Protocols in Pharmacology, vol. 58, no. 1, pp. 5.61.1-5.61.18, 2012.

[4] I. L. L. de Souza, B. C. Barros, G. A. de Oliveira et al., "Hypercaloric diet establishes erectile dysfunction in rat: mechanisms underlying the endothelial damage," Frontiers in Physiology, vol. 8, 2017.

[5] A. Castela, P. Gomes, V. F. Domingues et al., "Role of oxidative stress-induced systemic and cavernosal molecular alterations in the progression of diabetic erectile dysfunction," Journal of Diabetes, vol. 7, no. 3, pp. 393-401, 2015.

[6] F. B. M. Priviero, H. A. F. Toque, K. P. Nunes, D. G. Priolli, C. E. Teixeira, and R. C. Webb, "Impaired corpus cavernosum relaxation is accompanied by increased oxidative stress and up-regulation of the rho-kinase pathway in diabetic $(\mathrm{Db} / \mathrm{Db})$ mice," PLoS One, vol. 11, no. 5, article e0156030, 2016.

[7] H. Suenaga and K. Kamata, "Lysophosphatidylcholine activates extracellular-signal-regulated protein kinase and potentiates vascular contractile responses in rat aorta," Journal of Pharmacological Sciences, vol. 92, no. 4, pp. 348-358, 2003.

[8] F. Mcmurray, D. A. Patten, and M. E. Harper, "Reactive oxygen species and oxidative stress in obesity-recent findings and empirical approaches," Obesity, vol. 24, no. 11, pp. 2301-2310, 2016.

[9] B. Halliwell, "Reactive species and antioxidants. Redox biology is a fundamental theme of aerobic life," Plant Physiology, vol. 141, no. 2, pp. 312-322, 2006.

[10] T. Finkel and N. J. Holbrook, "Oxidants, oxidative stress and the biology of ageing," Nature, vol. 408, no. 6809, pp. 239-247, 2000.

[11] B. Halliwell and J. M. C. Gutteridge, Free Radicals in Biology and Medicine, Oxford University Press, USA, 5 edition, 2015.

[12] P. R. B. Broinizi, E. R. S. d. Andrade-Wartha, A. M. d. O. e. Silva et al., "Propriedades antioxidantes em subproduto do pedúnculo de caju (Anacardium occidentale L.): efeito sobre a lipoperoxidação e o perfil de ácidos graxos poliinsaturados em ratos," Revista Brasileira de Ciências Farmacêuticas, vol. 44, no. 4, pp. 773-781, 2008.

[13] B. P. Yu, "Cellular defenses against damage from reactive oxygen species," Physiological Reviews, vol. 74, no. 1, pp. 139-162, 1994.

[14] P. G. Pietta, "Flavonoids as antioxidants," Journal of Natural Products, vol. 63, no. 7, pp. 1035-1042, 2000.

[15] C. De Moraes and R. C. Sampaio, "Estresse oxidativo e envelhecimento: papel do exercício físico," Motriz. Revista de Educação Física. UNESP, vol. 16, no. 2, pp. 506-515, 2010.

[16] Y. Sato, J. X. He, H. Nagai, T. Tani, and T. Akao, "Isoliquiritigenin, one of the antispasmodic principles of Glycyrrhiza ularensis roots, acts in the lower part of intestine," Biological and Pharmaceutical Bulletin, vol. 30, no. 1, pp. 145-149, 2007.

[17] C. M. Sherwin, S. B. Christiansen, I. J. Duncan et al., "Guidelines for the ethical use of animals in applied ethology studies," Applied Animal Behaviour Science, vol. 81, no. 3, pp. 291-305, 2003.

[18] BRASIL, Ministério da Ciência, Tecnologia e Inovação, and Conselho Nacional de Experimentação Animal, Guia Brasileiro de Produção, Manutenção ou Utilização de Animais em Atividades de Ensino ou Pesquisa Científica: Fascículo 1: Introdução Geral, Ministério da Ciência, Tecnologia e Inovação, Brasília-DF, 2016.

[19] D. Estadella, L. M. Oyama, A. R. Dâmaso, E. B. Ribeiro, and C. M. Oller Do Nascimento, "Effect of palatable hyperlipidic diet on lipid metabolism of sedentary and exercised rats," Nutrition, vol. 20, no. 2, pp. 218-224, 2004.

[20] M. Radenkovic, V. Ivetic, M. Popovic, N. Mimica-Dukic, and S. Veljkovic, "Neurophysiological effects of mistletoe (Viscum album L.) on isolated rat intestines," Phytotherapy Research, vol. 20, no. 5, pp. 374-377, 2006.

[21] D. W. Howard, E. J. Lewis, B. J. Keller, and C. Smith, Histological Techniques for Marine Bivalve Molluscs and Crustaceans, NOAA/National Centers for Coastal Ocean Science, Oxford, MD, USA, 2nd edition, 2004.

[22] C. A. B. de Lira, R. L. Vancini, S. S. M. Ihara, A. C. da Silva, J. Aboulafia, and V. L. A. Nouailhetas, "Aerobic exercise affects C57BL/6 murine intestinal contractile function," European Journal of Applied Physiology, vol. 103, no. 2, pp. 215-223, 2008.

[23] C. C. Winterbourn, J. M. C. Gutteridge, and B. Halliwell, "Doxorubicin-dependent lipid peroxidation at low partial pressures of $\mathrm{O}_{2}$," Journal of Free Radicals in Biology \& Medicine, vol. 1, no. 1, pp. 43-49, 1985.

[24] W. Brand-Williams, M. E. Cuvelier, and C. Berset, "Use of a free radical method to evaluate antioxidant activity," $L W T$ Food Science and Technology, vol. 28, no. 1, pp. 25-30, 1995.

[25] R. R. Neubig, M. Spedding, T. Kenakin, A. Christopoulos, and International Union of Pharmacology Committee on Receptor Nomenclature and Drug Classification., "International union of pharmacology committee on receptor nomenclature and drug classification. XXXVIII. Update on terms and symbols in quantitative pharmacology," Pharmacological Reviews, vol. 55, no. 4, pp. 597-606, 2003.

[26] F. Bäckhed, H. Ding, T. Wang et al., "The gut microbiota as an environmental factor that regulates fat storage," Proceedings of the National Academy of Sciences of the United States of America, vol. 101, no. 44, pp. 15718-15723, 2004.

[27] D. W. Haslam and W. P. T. James, "Obesity," The Lancet, vol. 366, no. 9492, pp. 1197-1209, 2005. 
[28] J. J. Patel, M. D. Rosenthal, K. R. Miller, P. Codner, L. Kiraly, and R. G. Martindale, "The critical care obesity paradox and implications for nutrition support," Current Gastroenterology Reports, vol. 18, no. 9, p. 45, 2016.

[29] L. O. Pereira, R. P. d. Francischi, and A. H. Lancha Jr, "Obesidade: hábitos nutricionais, sedentarismo e resistência à insulina," Arquivos Brasileiros de Endocrinologia e Metabologia, vol. 47, no. 2, pp. 111-127, 2003.

[30] L. A. Velloso, "The brain is the conductor: diet-induced inflammation overlapping physiological control of body mass and metabolism," Arquivos Brasileiros de Endocrinologia \& Metabologia, vol. 53, no. 2, pp. 151-158, 2009.

[31] A. Tchernof and J. P. Després, "Pathophysiology of human visceral obesity: an update," Physiological Reviews, vol. 93, no. 1, pp. 359-404, 2013.

[32] J. C. Bornstein, M. Costa, and J. R. Grider, "Enteric motor and interneuronal circuits controlling motility," Neurogastroenterology \& Motility, vol. 16, no. s1, pp. 34-38, 2004.

[33] K. M. Sanders, S. D. Koh, T. Ordog, and S. M. Ward, "Ionic conductances involved in generation and propagation of electrical slow waves in phasic gastrointestinal muscles," Neurogastroenterology \& Motility, vol. 16, no. s1, pp. 100-105, 2004.

[34] C. M. Rembold, "Electromechanical and pharmacomechanical coupling," in Biochemistry of Smooth Muscle Contraction, M. Bárány, Ed., pp. 227-239, Elsevier, San Diego, CA, USA, 1996.

[35] L. C. da Cunha Araujo, I. L. L. de Souza, L. H. C. Vasconcelos et al., "Acute aerobic swimming exercise induces distinct effects in the contractile reactivity of rat ileum to $\mathrm{KCl}$ and carbachol," Frontiers in Physiology, vol. 7, 2016.

[36] V. Ballabeni, E. Barocelli, S. Bertoni, and M. Impicciatore, "Alterations of intestinal motor responsiveness in a model of mild mesenteric ischemia/reperfusion in rats," Life Sciences, vol. 71, no. 17, pp. 2025-2035, 2002.

[37] S. Bertoni, V. Ballabeni, L. Flammini, T. Gobbetti, M. Impicciatore, and E. Barocelli, "Intestinal chronic obstruction affects motor responsiveness of rat hypertrophic longitudinal and circular muscles," Neurogastroenterology \& Motility, vol. 20, no. 11, pp. 1234-1242, 2008.

[38] S. P. Weisberg, D. McCann, M. Desai, M. Rosenbaum, R. L. Leibel, and A. W. Ferrante Jr, "Obesity is associated with macrophage accumulation in adipose tissue," The Journal of Clinical Investigation, vol. 112, no. 12, pp. 1796-1808, 2003.

[39] K. P. Davies and A. Melman, "Markers of erectile dysfunction,” Indian Journal of Urology, vol. 24, no. 3, pp. 320-328, 2008.

[40] K. M. Azadzoi, T. Golabek, Z. M. Radisavljevic, S. V. Yalla, and M. B. Siroky, "Oxidative stress and neurodegeneration in penile ischaemia," BJU International, vol. 105, no. 3, pp. 404-410, 2010.

[41] C. Vlachopoulos, N. Ioakeimidis, and C. Stefanadis, "Biomarkers, erectile dysfunction, and cardiovascular risk prediction: the latest of an evolving concept," Asian Journal of Andrology, vol. 17, no. 1, pp. 17-20, 2015.

[42] V. H. Ozacmak, H. Sayan, S. O. Arslan, S. Altaner, and R. G. Aktas, "Protective effect of melatonin on contractile activity and oxidative injury induced by ischemia and reperfusion of rat ileum," Life Sciences, vol. 76, no. 14, pp. 1575-1588, 2005.

[43] J. Liu, H. C. Yeo, E. Overvik-Douki et al., "Chronically and acutely exercised rats: biomarkers of oxidative stress and endogenous antioxidants," Journal of Applied Physiology, vol. 89 , no. 1, pp. 21-28, 2000.
[44] M. L. Marquezi, H. A. Roschel, A. d. S. Costa, L. A. Sawada, and A. H. Lancha Jr, "Effect of aspartate and asparagine supplementation on fatigue determinants in intense exercise," International Journal of Sport Nutrition and Exercise Metabolism, vol. 13, no. 1, pp. 65-75, 2003.

[45] L. C. da Cunha Araujo, I. L. L. de Souza, L. H. C. Vasconcelos et al., "Chronic aerobic swimming exercise promotes functional and morphological changes in rat ileum," Bioscience Reports, vol. 35, no. 5, article e00259, 2015.

[46] D. del Rio, A. J. Stewart, and N. Pellegrini, “A review of recent studies on malondialdehyde as toxic molecule and biological marker of oxidative stress," Nutrition, Metabolism and Cardiovascular Diseases, vol. 15, no. 4, pp. 316-328, 2005.

[47] M. Giera, H. Lingeman, and W. M. A. Niessen, "Recent advancements in the LC- and GC-based analysis of malondialdehyde (MDA): a brief overview," Chromatographia, vol. 75, no. 9-10, pp. 433-440, 2012.

[48] J. D. Morrow, "Is oxidant stress a connection between obesity and atherosclerosis?," Arteriosclerosis, Thrombosis and Vascular Biology, vol. 23, no. 3, pp. 368-370, 2003.

[49] F. Brighenti, S. Valtueña, N. Pellegrini et al., "Total antioxidant capacity of the diet is inversely and independently related to plasma concentration of high-sensitivity C-reactive protein in adult Italian subjects," British Journal of Nutrition, vol. 93, no. 05, pp. 619-625, 2005.

[50] A. Floegel, D. O. Kim, S. J. Chung, S. I. Koo, and O. K. Chun, "Comparison of ABTS/DPPH assays to measure antioxidant capacity in popular antioxidant-rich US foods," Journal of Food Composition and Analysis, vol. 24, no. 7, pp. 10431048, 2011. 


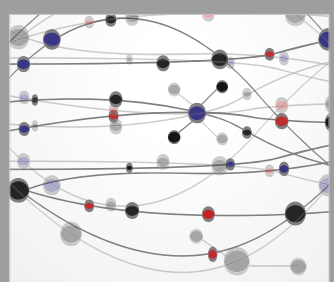

The Scientific World Journal
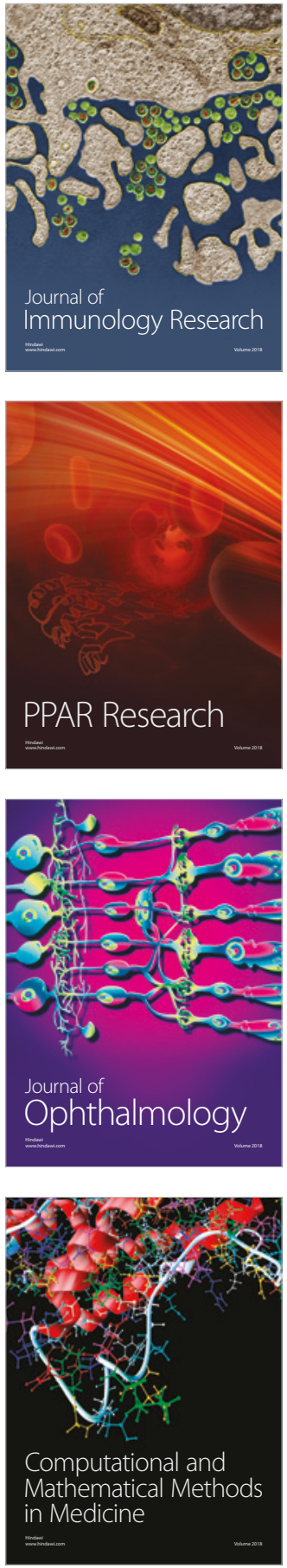

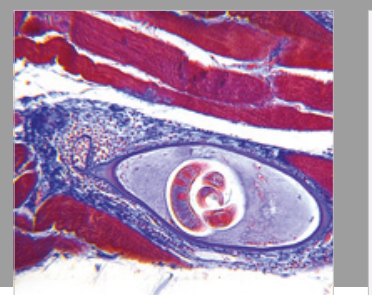

Gastroenterology Research and Practice

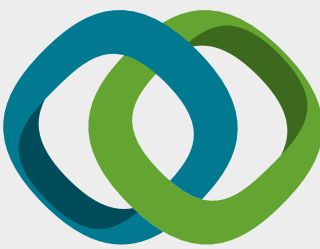

\section{Hindawi}

Submit your manuscripts at

www.hindawi.com
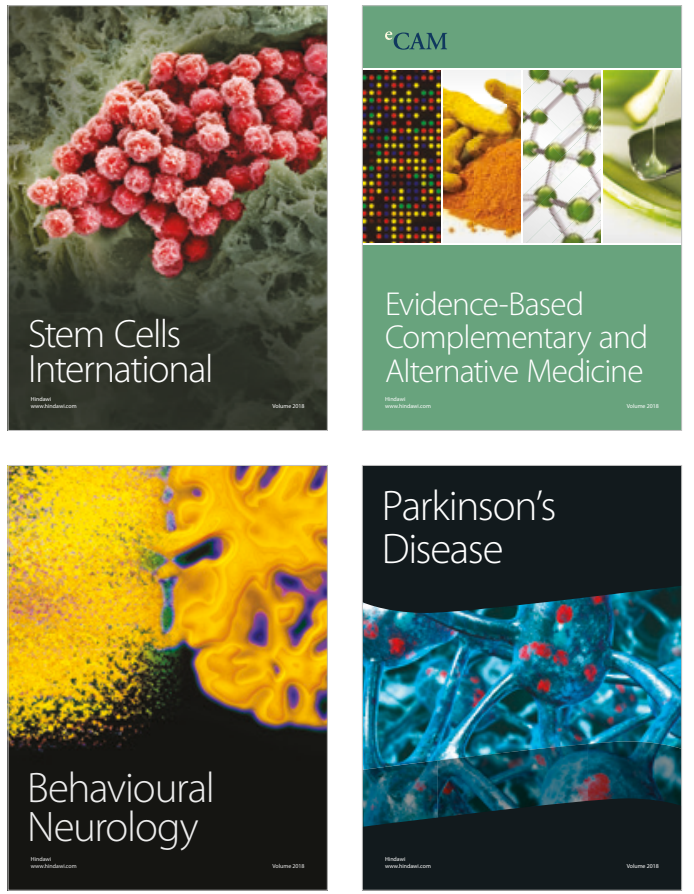

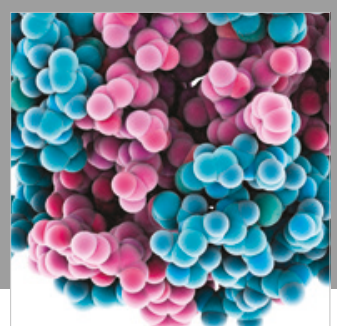

ournal of

Diabetes Research

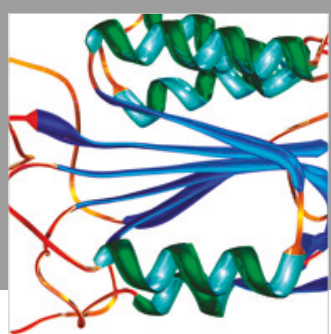

Disease Markers
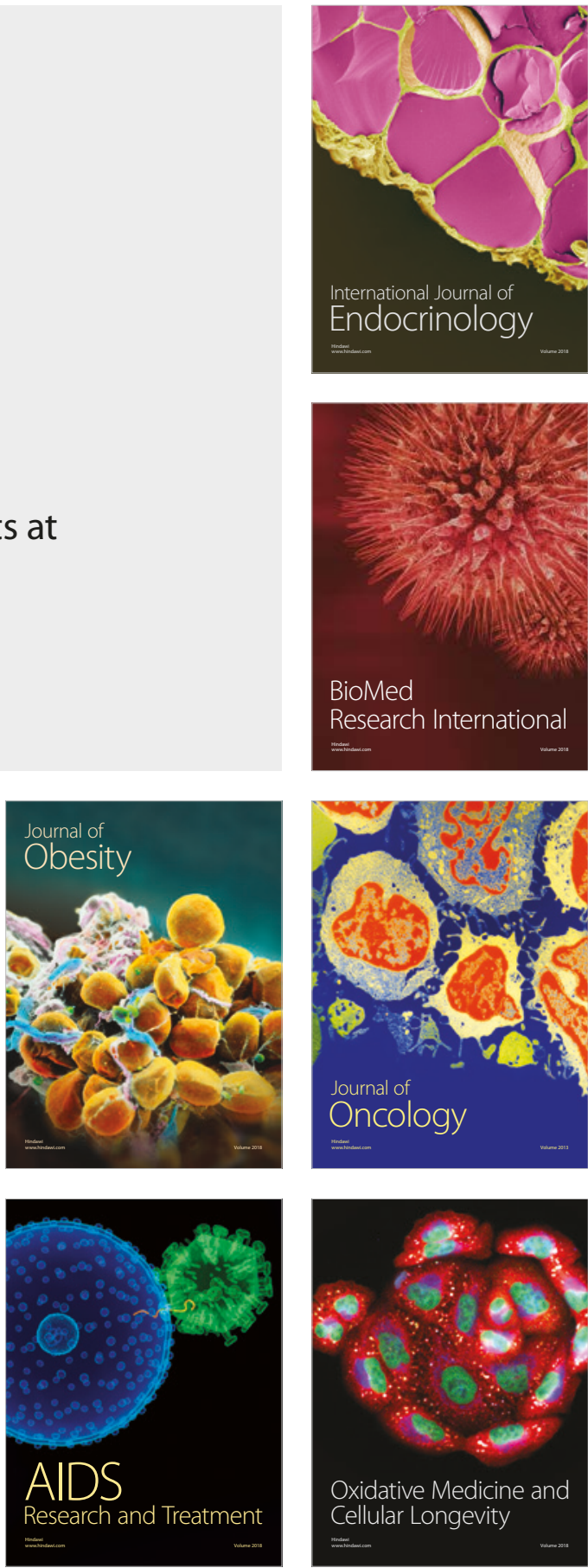